\title{
Normal Chromosomes in Mucosol Neuroma Variant of Medullary Thyroid Carcinoma Syndrome
}

\author{
H. NANKIN,* J. HYDOVITZ, and J. SAPIRA† \\ From the Department of Medicine, Montefiore Hospital and Presbyterian University Hospital, University of \\ Pittsburgh School of Medicine, Pittsburgh, Pennsylvania, U.S.A.
}

Medullary thyroid carcinoma represents 3.5-10\% of thyroid cancer (Woolner et al., 1961; Williams, Brown, and Doniach, 1966; Ibanez et al., 1967). It has attracted recent interest because this type of thyroid malignancy may be associated with phaeochromocytomas (Sapira et al., 1965) and/or parathyroid adenomas, and may produce calcitonin and ACTH (Steiner, Goodman, and Powers, 1968). The latter authors have suggested the name 'multiple endocrine neoplasia, type 2' (MEN-2) for this syndrome complex. An infrequent variant of this disorder is the mucosal neuroma syndrome (Williams and Pollock, 1966). Patients with mucosal neuromas may have: medullary thyroid carcinoma, parathyroid adenomas, phaeochromocytomas, a Marfanoid habitus, medullated corneal nerve fibres, and diverticulosis (Gorlin et al., 1968).

There is disagreement in two published reports concerning the cytogenetic evaluation of patients with medullary carcinoma of the thyroid. AlSaadi and Lieberman (1968) studied three patients with medullary carcinoma and two of their families. Each patient had a high percentage of aneuploidy (26-38\% of cells) with a chromosome missing most commonly in the $\mathrm{C}(6-\mathrm{X}-12)$ group. This abnormality was detected in several of the family members of the patients, including both parents and both brothers of an 11-year-old boy with medullary carcinoma and mucosal neuromas. In another report (Steiner et al., 1968) no numerical or structural abnormalities were found in the peripheral leucocytes or phaeochromocytoma cells obtained from two patients with MEN-2.

\footnotetext{
Recieved 3 March 1970.

* For Reprints: H. Nankin, M.D., Department of Medicine, Montefiore Hospital, 3459 Fifth Avenue, Pittsburgh, Pennsylvania 15213.

t National Institute of Mental Health Research Scientist Development Awardee Grant.

$\ddagger$ Calcitonin determinations were done by Dr. A. H. Tashjian.
}

We have had the opportunity to evaluate the peripheral leucocyte chromosomes in two patients with the mucosal neuroma variant of this syndrome. No consistent numerical or structural abnormalities could be identified in the chromosomes.

\section{Case Reports}

Case 1. A 32-year-old white male was admitted to hospital in August 1968 because of episodes of pounding headache, palpitation, and perspiration. The physical examination revealed a thin, hypertensive man with a palpable thyroid mass. Most striking was his Marfanoid appearance (thick lips, thickened tarsal plates, high arched palate, and pes cavus) and tongue neuromas (Fig 1). Hyperlaxity of wrist and metacarpal phalangeafo joints was found. Medullated corneal nerve fibres were found by slit-lamp examination. Barium enema revealed diverticulosis coli which could not be demonstrated after the surgical removal of his bilateral adrenal phaeochromocytomas.

He was readmitted for a total thyroidectomy and a left radical neck dissection. It was elected to do the right radical neck dissection separately. An amyloid-containing medullary carcinoma was found, which contained an increased concentration of calcitonin. $\neq$ In January 1969, the patient was admitted for the neck dissection, but developed appendicitis, and a plexiform neurofibroma was found in the appendectomy specimen. In February 1969 the right radical neck dissection was performed.

A 15-year-old nephew (son of the patient's brother) had the same physical appearance as the patient, but was asymptomatic and had no demonstrable neuromas. His evaluation (included catecholamines, vanillylmandelic acid (VMA), serum calcium determinations, and thyroid ${ }^{131}$ I Scan) was normal. Neither his father (the patient's brother) nor other family members had stigmata of the medullary thyroid carcinoma syndrome complex.

Case 2. A 12-year-old white girl was seen in May 1969 , with the complaint of an enlarging neck mass of 6 week's duration. The pulse and blood pressure were normal. She had multiple cafe au lait spots and Marfanoid features (high arched palate, thickening of the 

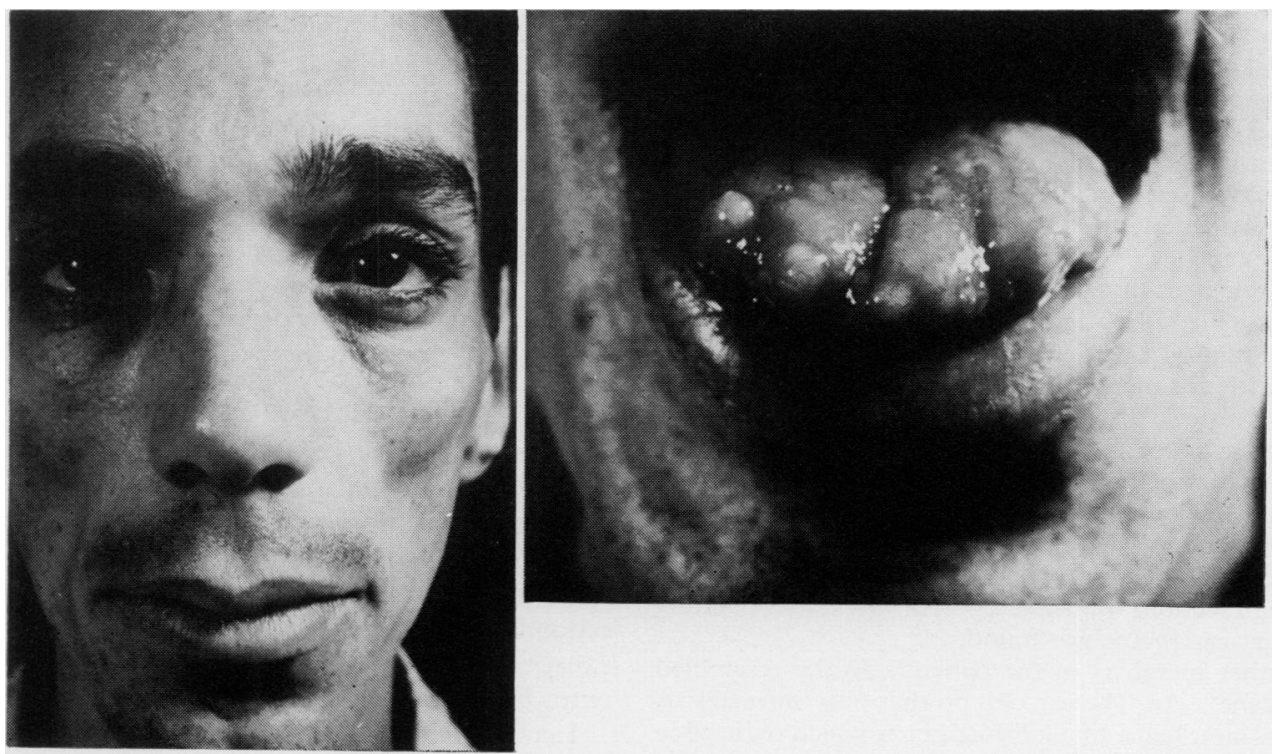

FIG. 1. Case 1 (a) Marfanoid appearance, heavy eyebrows, and thick lips; (b) tongue neuromas.

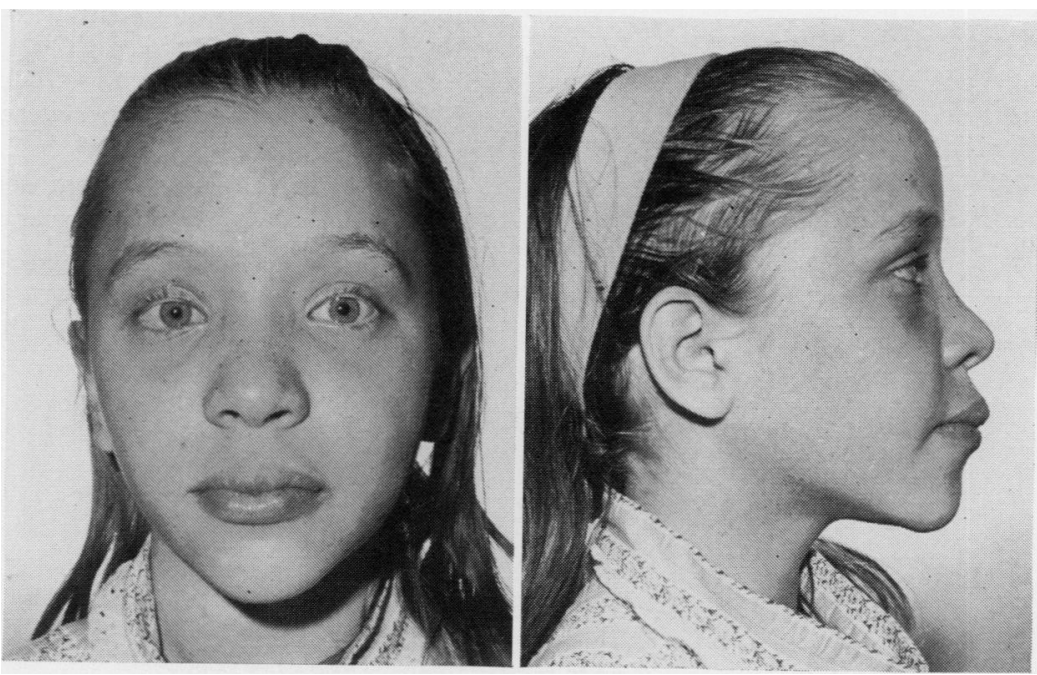

Fig. 2. Case 2 (a) and (b) Marfanoid appearance, thick lips, heavy eyebrows, and a broad nose with a slight saddle.

tarsal plate, bilateral pes cavus, pectus excavatum, and thick lips).

There were prominent scalp folds, orbital ridges, and eyebrows (Fig. 2). There were no neuromas in the eyelids or over the cornea, but there were several neuromas on the tip of the tongue. Hypertelorism was noted. The nose was broad with a slight saddle. Her voice was hoarse. The thyroid gland was enlarged (2-3 times normal), irregular, and firm. Several anterior cervical masses were noted bilaterally. There were early pubescent changes of the breasts. Prominent subcutaneous fat was noted over the pubic symphysis, and the labia majora were thickened, which contrasted with her otherwise lean physique. Hyperlaxity was noted in the fingers, 
wrists, and knees. Medullated corneal nerves were found by slit-lamp examination.

The laboratory data revealed normal serum calciums and urinary VMA, norepinephrine, epinephrine, metanephrines, and hydroxyproline. The chest $x$-ray revealed linear and granular pulmonary infiltrates (thought to be metastases) in both lung fields with the trachea displaced to the left. Diverticulosis was not found by barium enema.

The resected thyroid tumour revealed an amyloidcontaining medullary carcinoma which had an increased concentration of calcitonin.

The patient's mother had died in 1959 at age 28 with a mass in her neck which was first noted at about age 12 . The mother's face and physical characteristics were quite similar to that of Case 2. The initial histological diagnosis was malignant metastic tumour of the thyroid. The necropsy revealed metastases to the lungs and to an adrenal. The paraffin blocks of the necropsy were obtained and sections were made.* An amyloid-containing medullary carcinoma was found.

No other members of the patient's family resembled the patient. An 11-year-old brother was normal. A maternal aunt had a small diffuse goitre which reduced in volume coincident with administered thyroid hormone. The maternal grandmother died with carcinoma of the breast and the maternal grandfather died with prostatic carcinoma.

\section{Cytogenetic Studies}

Heparinized blood was obtained by venepuncture and allowed to sediment at room temperature. The cells were washed twice with MEM-Eagle (Flow Labs.). Duplicate cultures were grown in $1 \mathrm{oz}$. screw-top bottles containing $7.9 \mathrm{ml}$. of MEM-Eagle, $10^{7}$ cells, $2 \mathrm{ml}$. of autologous serum, and $0.1 \mathrm{ml}$. PHA (Burrough's-

* Repeat sections were studied by Dr. H. Mendelow.
Wellcome). Colcemid $(0.2 \gamma / \mathrm{ml}$.), was added during the final $2 \frac{1}{2}$ hours of culture (Nankin, 1970).

The cells were swelled with $0.9 \%$ sodium citrate, $\frac{\mathbb{D}}{\overparen{D}}$ fixed in two changes of a 1 to 1 solution of absolute ethanol and glacial acetic acid, and the chromosomes $\vec{\Rightarrow}$ were stained with Giemsa. Microscopy was done using $\stackrel{9}{\rightarrow}$ a Zeiss Photomicroscope, and 4 by 5 in. prints were made $\bar{C}$ of each spread. Chromosomes were analysed micro- 흠 scopically and the prints analysed separately by two ob- $\overline{\bar{S}}$ servers. Complete karyotypes were made of aneuploid cells and randomly from normal appearing cells.

\section{Results}

Cells from Case 1 were grown for 48 hours and $\vec{\omega}$ reveal 2 spreads with 47 chromosomes, 48 spreads with 46 chromosomes, 2 spreads with 45 chromo- ̣̂. somes, and 1 spread with 44 chromosomes. The latter spread lacked both a $C$ and an $F$. The reremaining 52 cells appear to have $15 \mathrm{C}$ chromosomes $A$ except for one having 47 chromosomes and an 을 extra C.

Leucocytes were obtained twice from Case $2 \overrightarrow{0}$ and were cultured for 48 hours and 72 hours, respectively. 50 cells were examined from the 48hour culture-1 had 45 chromosomes and lacked a No. 2, the remaining cells had 46 chromosomes. The cells cultured for 72 hours revealed 40 spreads with 46 chromosomes, 3 with 45 , and 1 with 48 chromosomes. In the spread with 43 chromosomes. two $\mathrm{C}$ and one $\mathrm{F}$ chromosomes were missing. Tho results are tabulated in Table I.

For comparison, the chromosome analysis of leucocytes obtained from 10 patients with a variety of disorders was reviewed. None of these patients had a 'chromosomal' disorder, was under stress, or received radiomimetic drugs or radiotherapy.

TABLE I

RESULTS OF CHROMOSOME ANALYSIS IN CASES 1 AND 2

\begin{tabular}{|c|c|c|c|c|c|c|}
\hline & \multicolumn{6}{|c|}{ No. of Chromosomes } \\
\hline & $<44$ & 44 & 45 & 46 & 47 & Totals \\
\hline $\begin{array}{l}\text { Case } 1 \\
\text { No. of cells } \\
\text { Karyotypes } \\
\text { Comments }\end{array}$ & & $\begin{array}{c}1 \\
-(\stackrel{C}{\mathbf{C}}, \mathbf{F}) \\
\end{array}$ & $\begin{array}{c}2 \\
2 \\
-(D),-(G) \\
\end{array}$ & $\begin{array}{r}48 \\
7\end{array}$ & $\begin{array}{c}2 \\
2 \\
+(C),+(F) \\
\end{array}$ & $\begin{array}{l}53 \\
12\end{array}$ \\
\hline $\begin{array}{c}\text { Case } 2 \text { (48 hr.) } \\
\text { No. of cells } \\
\text { Karyotypes } \\
\text { Comments } \\
\end{array}$ & & & $\begin{array}{c}1 \\
1 \\
-(\text { No. } 2) \\
\end{array}$ & $\begin{array}{l}49 \\
10\end{array}$ & & $\begin{array}{l}50 \\
11\end{array}$ \\
\hline $\begin{array}{c}\text { Case } 2(72 \mathrm{hr} .) \\
\text { No. of cells } \\
\text { Karyotypes } \\
\text { Comments }\end{array}$ & $\begin{array}{c}1 \\
1 \\
-(2 \mathrm{C}, \mathrm{F})\end{array}$ & & $\begin{array}{c}3 \\
2 \\
-(F),-(G) \\
-(G)\end{array}$ & $\begin{array}{r}40 \\
8\end{array}$ & & $\begin{array}{l}44 \\
11\end{array}$ \\
\hline Totals & 1 & 1 & 6 & 137 & 2 & 147 \\
\hline
\end{tabular}

Note: Extra or deleted chromosomes in the aneuploid cells are indicated in parentheses. 
TABLE II

SUMMARY OF RESULTS IN 10 CONTROL PATIENTS

\begin{tabular}{|c|c|c|c|c|c|c|}
\hline \multirow{2}{*}{ Control No., Age, and Sex } & \multirow{2}{*}{$\begin{array}{l}\text { Total } \\
\text { Cells }\end{array}$} & \multicolumn{5}{|c|}{ No. of Chromosomes } \\
\hline & & 44 & 45 & 46 & 47 & $=47$ \\
\hline $\begin{array}{l}\text { 1, } 9 \text { yr. female } \\
\text { (suspected Turner) } \\
\text { 2, } 38 \text { yr., female } \\
\text { (polycystic kidneys) } \\
\text { 3, } 18 \text { yr., female } \\
\text { (suspected Turner) } \\
\text { 4, 19 yr., male } \\
\text { (delayed adolescence) } \\
\text { 5, } 34 \text { yr., male } \\
\text { (infertile) } \\
\text { 6, } 17 \text { yr., male } \\
\text { (delayed adolescence) } \\
\text { 7, 62 yr., male } \\
\text { (thin, pectus excavatum) } \\
\text { 8, } 47 \text { yr., male } \\
\text { (Kallmann's syndrome) } \\
\text { 9, 10 yr., male } \\
\text { (slow growth) } \\
\text { 10, } 14 \text { yr., male } \\
\text { (gynaecomastia) }\end{array}$ & $\begin{array}{l}30 \\
30 \\
24 \\
30 \\
30 \\
15\end{array}$ & $-(2 G)$ & 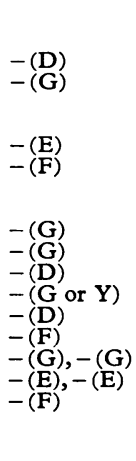 & $\begin{array}{l}30(46 \mathrm{XX}) \\
28(46 \mathrm{XX} ; \\
23(46 \mathrm{XX}) \\
28(46 \mathrm{XY}) \\
15(46 \mathrm{XY}) \\
27(46 \mathrm{XY}) \\
25(46 \mathrm{XY}) \\
17(46 \mathrm{XY}) \\
24(46 \mathrm{XY}) \\
26(46 \mathrm{XY})\end{array}$ & & $\begin{array}{l}+(\mathrm{C}, \mathrm{D}, \mathrm{E}) \\
+(\mathrm{B}, \mathrm{C}, \mathrm{G}, 3 \mathrm{E})\end{array}$ \\
\hline Totals & 262 & 2 & 15 & 243 & & 2 \\
\hline
\end{tabular}

Note: Aneuploid spreads are listed in the appropriate column. Extra or missing chromosomes are indicated in parentheses.

These cells were harvested after 48 hours of in vitro growth. A total of 262 cells was analysed, of which 243 had 46 chromosomes. Two cells had 44 chromosomes, 15 cells had 45 chromosomes, and 2 cells had more than 47 chromosomes. In none of these patients was a $\mathrm{C}$ missing. These results are tabulated in Table II.

\section{Discussion}

Since there are limited data concerning chromosomes in this syndrome complex, it seemed warranted to do a cytogenetic evaluation of these patients. In a recent review (Block, 1969), it was noted that a high incidence of missing $C$ group chromosomes had been found in the peripheral leucocytes of patients with the medullary thyroid carcinoma syndrome of the familial variety (referring to the work of Al-Saadi and Lieberman, 1968). It was emphasized that the true value of this determination in detecting subclinical or predisposed patients is unknown. In both our patients there was evidence of familial occurrence of this disorder.

Our 2 patients had a hypodiploid number of chromosomes in $5.45 \%$ of the spreads analysed, while the 10 randomly selected controls had an incidence of $6.5 \%$. Therefore, an increased tendency to hypodiploid spreads cannot be confirmed. No other consistent abnormality was noted. Two cells, one from Case 1 and one from Case 2 were missing one and two $\mathrm{C}$ group chromosomes, respectively, while no $\mathrm{C}$ group chromosomes were missing in the 10 controls. This is of questionable significance. We have noted a $\mathrm{C}$ to be missing in one of 15-25 spreads in the following subjects: in a female pseudohermaphrodite, in a patient who had been on Myleran for thrombocytosis, in a small menstruating patient under treatment for acute atopic asthma, in a fasting obese girl, and in a patient with Gardner's syndrome shortly after abdominal surgery.

\section{Summary}

No consistent tendency to hypodiploid spreads or other chromosomal abnormalities was found in two patients with the mucosal neuroma variant of the medullary thyroid carcinoma syndrome.

The authors wish to thank Miss Carol Fear for her technical assistance.

\section{REFBRENCES}

Al-Saadi, A., and Lieberman, L. (1968). Cytogenetic study in medullary carcinoma of thyroid (Abstract). Program American Thyroid Association Meeting, p. 69.

Block, M. S. (1969). Medullary thyroid carcinoma: A component of an interesting endocrine syndrome. Ca., Mar/Apr, 19, 74-79.

Gorlin, R. J., Sedano, H. O., Vickers, R. A., and Červenka, J. (1968). Multiple mucosal neuromas, pheochromocytoma and medullary carcinoma of the thyroid-a syndrome. Cancer (Philadelphia), 22, 293-299.

Ibanez, M. L., Cole, V. W., Russell, W. O., and Clark, R. L. (1967). Solid carcinoma of the thyroid gland. Cancer (Philadelphia), 20 
Nankin, H. R. (1970). In vitro alteration of satellite association and nucleolar persistence in mitotic human lymphocytes. Cytogenetics, 9, 42-51.

Sapira, J. D., Altman, M., Vandyk, K., and Shapiro, A. P. (1965). Bilateral adrenal pheochromocytoma and medullary thyroid carcinoma. New England fournal of Medicine, 273, 140-143.

Steiner, A. L., Goodman, A. D., and Powers, S. R. (1968). Study of a kindred with pheochromocytoma, medullary thyroid carcinoma, hyperparathyroidism and Cushing's disease: multiple endocrine neoplasia, type 2. Medicine, 47, 371-409.
Williams, E. D., Brown, C. L., and Doniach, I. (1966). Pathological and clinical findings in a series of 67 cases of medullary carcinoma of the thyroid. Fournal of Clinical Pathology, 19, 103-113.

, and Pollock, D. J. (1966). Multiple mucosal neuromata with endocrine tumors: a syndrome allied to von Recklinghausen's disease. Fournal of Pathology and Bacteriology, 91, 71-80.

Woolner, L. B., Beahrs, O. H., Black, B. M., McConahey, W. M. and Keating, F. R., Jr. (1961). Classification and prognosis of thyroid carcinoma, a study of 885 cases observed over a thirty year period. American fournal of Surgery, 102, 354-387. 